\title{
Construct validity of writing motivation Questionnaire
}

\author{
Validación del cuestionario de motivación a la escritura
}

\author{
Devdulal Dutta Roy \\ Indian Statistical Institute
}

\begin{abstract}
The article reports results of two consecutive studies designed to understand construct validity of writing motivation and to examine its utility in the prediction of academic achievement. In first study, data were collected from 884 students of primary education through writing motivation questionnaire with seven domains (Dutta Roy, 2003). Correspondence analysis reveals two latent traits (intrinsic and extrinsic) of writing motivation. In the second study, writing motivation questionnaire was administered to 200 students and their academic performances in schools were collected. Results reveal inverse relation between latent traits. Composite scores of intrinsic writing motivation were positively and those of extrinsic writing motivation were negatively correlated with academic performance..
\end{abstract}

Key words: Writing motivation, validity, academic performance, primary education.

\section{RESUMEN}

Esta investigación reporta los resultados de dos estudios consecutivos diseñados para entender la validez del constructo de la motivación a la escritura y examina su utilidad en la predicción del rendimiento académico. En el primer estudio, los datos fueron obtenidos de 884 estudiantes de educación primaria a través del cuestionario de motivación a la escritura con siete dominios (Dutta Roy, 2003). Los análisis de correspondencia evidenciaron dos categorías latentes (intrínsecas y extrínsecas) de la motivación a la escritura. En el segundo estudio, el cuestionario de motivación a a escritura fue aplic ado a 200 estudiantes y en los cuales se obtuvo además el registro de su rendimiento académico. Los resultados revelaron una relación inversa entre las categorías latentes. Los puntajes obtenidos para la motivación intrínseca a la escritura estuvieron positivamente asociados, mientras que los observados para la motivación extrínseca a la escritura se correlacionaron negativamente con el rendimiento académico.

Palabras clave: Motivación a la escritura, validación, rendimiento académico, educación primaria. OPEN JOURNAL SYSTEM, BIBLIOTECA VIRTUAL DE PSICOLOGIA (ULAPSY-BIREME), DIALNET y GOOGLE SCHOLARS. Algunos de sus articulos aparecen en SOCIAL SCIENCE RESEARCH NETWORK y está en proceso de inclusion en diversas fuentes y bases de datos internacionales. INTERNATIONAL JOURNAL OF PSYCHOLOGICAL RESEARCH is included in PSERINFO, CENTRO DE INFORMACIÓN PSICOLÓGICA DE COLOMBIA, OPEN JOURNAL SYSTEM, BIBLIOTECA VIRTUAL DE PSICOLOGIA (ULAPSY-BIREME), DIALNET and GOOGLE SCHOLARS. Some of its articles are in SOCIAL SCIENCE RESEARCH NETWORK, and it is in the process of inclusion in a variety of sources and international databases. 
International Journal of Psychological Research, 2009. Vo. 3. No. 2.

ISSN impresa (printed) 2011-2084

ISSN electrónica (electronic) 2011-2079

Development of any theoretical construct requires examination of construct validity. Construct validity is a necessary condition for theory development and testing. It pertains to the degree of corres pondence between constructs and measures. The extent to which the questionnaire measures a theoretical construct for which the questionnaire has been developed is called construct validity. High construct validity indicates higher accounting of variances from the same construct by the sets of variables measured by questionnaire.

Every variable is likely to reflect a variety of constructs as well as purely random error. The following equation illustrates this fact (Judd, 1981) :

$$
\mathrm{Y}=\mathrm{C} 1+\mathrm{C} 2+\ldots \ldots \ldots \ldots \ldots \ldots \ldots . \mathrm{Cn}+\mathrm{E}
$$

Where $\mathrm{Y}$ refers to measured variable, the set of $\mathrm{C}$ refers to a set of unmeasured theoretical constructs that contribute to variation in $\mathrm{Y}$. And $\mathrm{E}$ refers to the random error or simply 'noise' in the measurement of Y. Factorial, convergent and discriminant validities are three basic techniques to assess construct validity. Factor analys is is used for extracting latent traits or factors. Correspondence analysis instead of usual factor analysis provides information about latent traits through correspondence map. Correspondence map provides extent of closeness among sets of variables. Close locations occur when the variables are interrelated with each other. The higher the inter correlations, the higher the correspondence as variances of variables occupy same places on the map. Therefore, based on extent of locations, one can assume latent traits or factors. Hierarchical cluster analysis is also another statistical model to explore latent relation among psychological traits. Using Euclidean distance matrix, it extracts latent phenomenon. Study 1 tends to explore latent traits of writing motivation.

Writing motivation: Writing serves as an instrumental tool at the primary educational level, because, in addition to providing a vehicle of self-expression and critical analysis, it provides purposeful hardship more toward academic achievement by organizing thoughts in a systematic manner. Writing motivation is a process through which an individual energizes to express ideas in writing. Motivation to write comes from appraisal of cognitions (Dutta Roy, 2004). A questionnaire was developed by Dutta Roy (2003) to assess 7 domains of writing motivation. These are writing for documentation (wDoc), emotional expression (wEmo), creative expression (wCrea), mastery over writing (wAch), being loved by others (wAff), being recognized by others (wRecog), and being punished by others (wPunish). Current study examined latent relations among seven subtests or traits of writing motivation. Validation of latent traits was examined using convergent
Dutta Roy, D. (2010). Construct validity of writing motivation Questionnaire. International Journal of P sychological Research, 3(2), XX-XX.

and discriminant properties of writing motivation in study 2 .

\section{STUDY 1}

Objective of this study was to explore latent traits of writing motivation questionnaire. Latent traits indicate underlying relation among inter related variables. This is important for theory development.

\section{METHODS}

\section{Sample}

Sampling was done in two stages- (a) selection of sample schools from four school types- Government, Government aided, corporation and Missionary schools under the West Bengal Board of Primary Education (b) selection of sample students. For selection of sample schools lists of government, Government aided, Kolkata Corporation and Missionary schools were collected from different sources -Calcutta District Primary School Council, Calcutta Municipal Corporation and Police stations of different areas. Data were collected from 3 Government schools, 5 schools financially aided by the Government of West Bengal, 7 schools of Kolkata Corporation and 3 missionary schools under the West Bengal Board of Primary Education. In sampling, attention was paid to the equal representation of schools across north, south, east, west and central Kolkata. Finally 884 data were collected from students of Government, Government aided, corporation and of Missionary schools. Thus simple stratified random sampling was followed in sampling the students from 4 strata - 5 zones of Kolkata (North, South, Central, East, and West) X 4 school types (Government, Government-aided, Corporation and Missionary schools) $\mathrm{X}$ 2 grades (grades III and IV) X 2 genders (boy and girl).

\section{Instrument}

Writing motivation questionnaire or WMQ (Dutta Roy, 2003) includes 42 questions measuring 7 writing motives - wDoc, wEmo, wAch, wCrea, wRecog, wAff, wPunish. Scoring is based on subjects' preference to number of alternative answers for each category of variable. For each variable, maximum possible score is six and the minimum possible score is zero. Some items of the questionnaire are given below:

1. Your language teacherasks you to write a letter to one of your friends about the annual function of your school. What will you write in the letter?

(a) Complete description of the ceremony

(b) My pleasant feeling about the occasion 
International Journal of Psychological Research, 2010. Vo. 3. No. 2. ISSN impresa (printed) 2011-2084

ISSN electrónica (electronic) 2011-2079

2. You have been asked to submit an article in your school tomorrow. But it has not been finished. On the other hand, your mood is off for misunderstanding with your friend. You want to write a letter to him/her. Which one do you write first?

(a) If I do not finish writing for the school I will be abused .So I will write the article first

(b) I will write the letter to my friend first.

Test-retest reliability of WMQ was examined by (a) product moment correlation between scores of $7 \mathrm{sub}$ tests using 70 students of same school within interval of 8 months and (b) paired t-tests. Results noted very high correlation coefficients (ranged from 0.61 to 0.99 ) between the periods. Except creativity, all domains were higher than 0.93. Paired t-tests show insignificant mean differences between periods for 6 items out of 22 . In other words, $72 \%$ of total item means in both sessions did not differ significantly. Item-total correlation was used to assess content validity of each subtest using 516 samples. All coefficients were significant at 0.01 level (Dutta Roy, 2003).

\section{Analysis of data}

Initially, data quality of 7 subtests was examined through box whisker plot. Next correspondence analys is (CA) was used to determine extent and nature of correspondence or association among the subtests. It is assumed that when research variables are internally consistent, they lie very close to each other in the correspondence map. Latent trait of the questionnaire was explored by the analysis of close association among subtests. Significance of as sociations is tested by chi-square analysis. CA provides a joint plot of points representing both the rows and columns of the table. In CA, instead of trying to compare rows using proportions, smaller number of coordinates are created so that each successive coordinate axis accounts for a decreasing portion of the total association between the rows and columns as represented by the familiar Pears on Chi-square statistics. This reduction is also noted in principal component analysis. CA is often called as PCA for categorical data. The first coordinate accounts for the largest part of the total association, the second for the next largest part and so on like PCA. Correspondence analysis (CA) is an exploratory technique to investigate magnitude and the substantive nature of association between the row and column categories of cross tabulation rather than to confirm or reject hypothesis about the underlying process which generates the data (Greenacre and Blasius, 1994). It is the technique to display row and column variables of a two way contingency table graphically as points on a corresponding lower dimensional vector spaces. According to Andrews (1978) graphical display of data is
Dutta Roy, D. (2010). Construct validity of writing motivation Questionnaire. International Journal of Psychological Research, 3(2), 6-11.

comprehensible to human minds, thus uncovering structure of the data and detecting departure, if any, from the structure.

CA follows certain steps as (I) testing independence between row and column variables by chisquare analysis. Significance of chi-square represents that CA provides a "strong model" of the row column dependence; (II) assigning weights (mass) to the row and columns variables by dividing total row or column frequencies by the total sample size. This mass has important role in plotting the points on axis; (III) extracting factors from row and column variables by principal component analysis. Factor extraction helps in identifying a sub-space of lower dimensionality which comes close to the points presented by column and also row variables; (IV) graphical presentation of the points of row and column variables on low dimensional plane, usually two dimensional planes.

Since CA follows principal component analysis of a set of row and column variables, it is expected that $\mathrm{CA}$ possibly would provide more information about data structure, especially closeness of row and column variables than simple frequency or percentage analysis of data. To prove findings of $\mathrm{CA}$, hierarchical fcluster analysis was made.

\section{RESULTS}

\section{Box whisker plot}

Figure 1 shows no outlier in the distribution of 7 sub tests suggesting good data quality in all the measures. Medians of four subtests namely wDoc, wEmo, wAch, and wCrea were higher than other subtests as wRecog, wAff, wPunish. This suggests that students have high preference to the above four for writing in comparis on with later three.

Figure 1. Box-whisker plot of subtests of the writing motivation questionnaire.

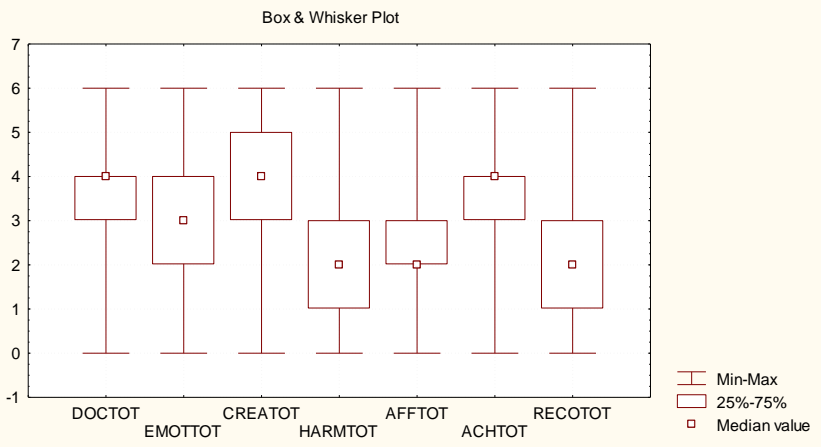

International Journal of Psychological Research 
International Journal of Psychological Research, 2009. Vo. 3. No. 2.

ISSN impresa (printed) 2011-2084

ISSN electrónica (electronic) 2011-2079

\section{Correspondence analysis}

Frequency data of input table (Table 1) were used for correspondence analysis through STATISTICA'99. The table included two categories of data. Rows were 7
Dutta Roy, D. (2010). Construct validity of writing motivation Questionnaire. International Journal of P sychological Research, 3(2), XX-XX.

subtests and columns were 7 scoring categories as S_0 (score 0$),$ S_1(score 1), S_2(score 2$)$ S_3, (score 3), S_4 (score 4), S_5 (score 5), S_6 (score 6). Initial analysis shows strong

Table 1. Distribution of scoring categories across seven subtests

\begin{tabular}{|c|c|c|c|c|c|c|c|c|c|c|c|c|c|c|}
\hline & S_0 & & S_1 & & S_2 & & S_3 & & S_4 & & S_5 & & S_6 & \\
\hline & $\mathrm{f}$ & $\%$ & $\mathrm{f}$ & $\%$ & f & $\%$ & $\mathrm{~F}$ & $\%$ & f & $\%$ & $\mathrm{f}$ & $\%$ & $\mathrm{f}$ & $\%$ \\
\hline wDoc & 1 & 0.43 & 29 & 3.02 & 113 & 8.61 & 200 & 12.35 & 448 & 27.74 & 166 & 20.42 & 26 & 7.88 \\
\hline wEmo & 14 & 6.01 & 79 & 8.24 & 166 & 12.65 & 288 & 17.79 & 305 & 18.89 & 127 & 15.62 & 4 & 1.21 \\
\hline wCrea & 2 & 0.86 & 20 & 2.09 & 94 & 7.16 & 191 & 11.80 & 240 & 14.86 & 219 & 26.94 & 217 & 65.76 \\
\hline wAch & 8 & 3.43 & 28 & 2.92 & 93 & 7.09 & 323 & 19.95 & 286 & 17.71 & 192 & 23.62 & 53 & 16.06 \\
\hline wAff & 29 & 12.45 & 197 & 20.54 & 335 & 25.53 & 246 & 15.19 & 125 & 7.74 & 38 & 4.67 & 13 & 3.94 \\
\hline wPunish & 130 & 55.79 & 323 & 33.68 & 264 & 20.12 & 153 & 9.45 & 79 & 4.89 & 31 & 3.81 & 3 & 0.91 \\
\hline wRecog & 49 & 21.03 & 283 & 29.51 & 247 & 18.83 & 218 & 13.47 & 132 & 8.17 & 40 & 4.92 & 14 & 4.24 \\
\hline Total & 233 & 100 & 959 & 100 & 1312 & 100 & 1619 & 100 & 1615 & 100 & 813 & 100 & 330 & 100 \\
\hline
\end{tabular}

model of row and column dependence (Chi-square $(36)=3004.7, \quad p<0.0001)$ suggesting dispersion of scores across subtests. All measures of writing motivation can be explained in terms of two broad dimensions accounting for $91.03 \%$ of total variances (Table 2 ).

Table 2. Eigen values and Inertia for all Dimensions

\begin{tabular}{l|r|r|r|r|r}
\hline & $\begin{array}{l}\text { Singular } \\
\text { Values }\end{array}$ & $\begin{array}{l}\text { Eigen- } \\
\text { values }\end{array}$ & $\begin{array}{l}\text { Percent of } \\
\text { inertia }\end{array}$ & $\begin{array}{l}\text { Cumulative } \\
\text { percent }\end{array}$ & $\begin{array}{l}\text { Chi- } \\
\text { square }\end{array}$ \\
\hline 1 & 0.56 & 0.31 & 70.74 & 70.74 & 2125.60 \\
\hline 2 & 0.30 & 0.09 & 20.29 & 91.03 & 609.52 \\
\hline 3 & 0.16 & 0.02 & 5.54 & 96.57 & 166.61 \\
\hline 4 & 0.11 & 0.01 & 2.53 & 99.11 & 76.13 \\
\hline 5 & 0.06 & 0.00 & 0.88 & 99.99 & 26.46 \\
\hline 6 & 0.01 & 0.00 & 0.01 & 100.00 & 0.42 \\
\hline
\end{tabular}

If we assume category 3 as the cut-off point to study high (category 4 to 6) and least preferred (category 0 to 2) writing motivation. It is noted that $65.11 \%, 44.35 \%$, $68.77 \%$ and $54.02 \%$ of responses are in the high category for wDoc, wEmo, wCrea, wAch successively. On the other side, $17.9 \%, 11.5 \%$ and $18.92 \%$ responses are in the low category for wAff, wPunish and wRecog successively. This suggests that students feel motivation to write for creative expression, documentation and mastery over writing. Correspondence map (Figure 2) exhibits two broad clusters of writing motives. First cluster includes wDoc, wEmo, wCrea, wAch whereas second cluster includes wAff,
wPunish and wRecog. Furthermore, hierarchical cluster analysis (Figure 3) was used to validate findings of corres pondence analysis. Cluster analys is clearly draws line between two clusters extracted by CA. First cluster includes measures of 4 writing motivation and second cluster includes measures of 3 writing motivation. Since first four variables represent motivation to write for own sake, this is called intrinsic writing motivation. Second cluster represents writing for other's sake. This is called extrinsic writing motivation. Measures of intrinsic writing motivation were more close to high scoring categories S_4, S_5, S_6 than the variables of extrinsic writing motivation. This supports earlier findings about more preference to intrinsic writing motivation.

Figure 2: Correspondence Map of Writing Motivation.

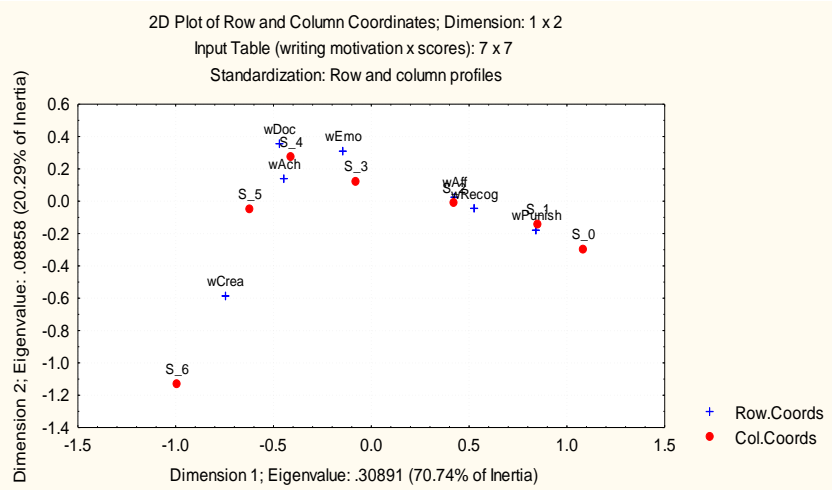


International Journal of Psychological Research, 2010. Vo. 3. No. 2. ISSN impresa (printed) 2011-2084

ISSN electrónica (electronic) 2011-2079

Figure 3: Clusters of 7 writing motivation measures.

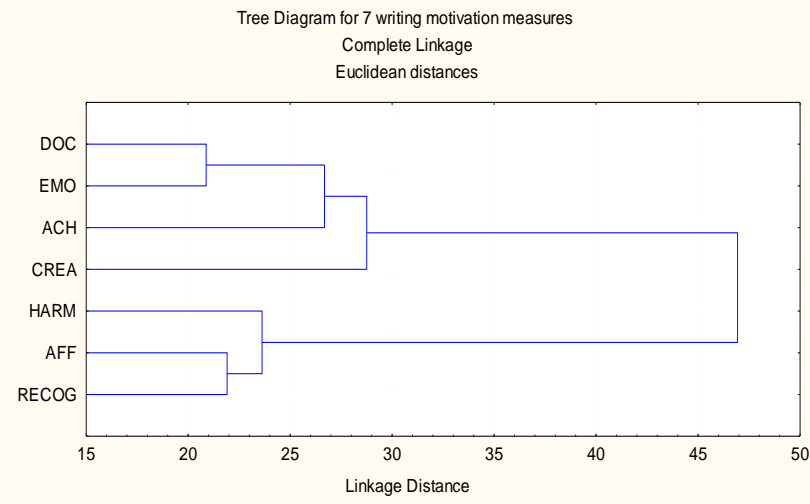

DISCUSSION

When theoretically assumed constructs are internally consistent they form cluster. Writing motivation questionnaire includes 7 constructs - wDoc, wEmo, wAch, wCrea, wRecog, wAff, and wPunish. Correspondence analysis reveals two clusters named as intrinsic and extrinsic writing motivation. Intrinsic cluster consisted of wDoc, wEmo, wAch, wCrea denotes motivation to write for own sake and extrinsic cluster consisted of wAff, wRecog and wPunish denotes writing motivation for other's sake. Extracting two clusters as assumed suggest factorial validity of writing motivation questionnaire. Results also revealed that children preferred intrinsic to extrinsic writing motivation. . Out of four measures of of intrinsic motivation cluster, children prefer more wCrea and wDoc,

And out of 3 contents of extrinsic motivation cluster, children least preferred wPunish. This indicates that intrinsically motivated children wanted to write for creative expression and documentation. On the other hand, extrinsically motivated children wanted to write in order to avoid punishment. This finding is important in designing writing motivation strategies for children. Convergent and discriminating validities are useful to validate extracted factors with available theories. Study 2 examined these by examining correlation between two constructs and their relation with academic performance.

\section{STUDY 2}

Objective of this study was to examine convergent and discriminant validity of two latent traits extracted in the study 1 . In estimation of convergent validity, attention is paid to examine whether extracted factor is correlated with theoretical measure or not. For example, intrinsic writing motivation is supposed to be correlated with academic performance as due to own desire when a child writes, his
Dutta Roy, D. (2010). Construct validity of writing motivation Questionnaire. International Journal of Psychological Research, 3(2), 6-11.

breadth of knowledge increases. And breadth of knowledge is related to academic performance (Stanovich and Cunningham, 1992). Likewise, in estimating discriminant validity, attention is paid to understand whether the extracted factor is uncorrelated with different theoretical concepts or not. It describes the degree to which the operationalization is not similar to (diverges from) other operationalizations that it theoretically should not be similar to Campbell and Fiske (1959). Another approach in estimation of discriminant validity is examination of negative correlation between extracted factors and theoretical measure. Campbell and Fiske (1959) introduced the concept of discriminant validity within their discussion on evaluating test validity. They stres sed the importance of using both discriminant and convergent validation techniques when assessing new tests. Study 2 aims at correlating writing motivation with academic performance of students to examine its convergent and discriminant validity. It is assumed that the more intrinsic writing motivation is correlated positively with academic performance, the more is the convergent validity. On the other hand, the more extrinsic writing motivation is correlated negatively with academic performance, the more is discriminant validity of the questionnaire.

\section{Method}

Writing motivation questionnaire or RMQ (Dutta Roy, 2003) was administered to 200 students of classes III (50 boys and 50 girls) and IV (50 boys and 50 girls) of one school. Their last examination marks in different subjects were obtained for ass essment of academic achievement.

\section{RESULTS \& DISCUSSION}

Initially, composite scores of intrinsic writing motivation were estimated by adding the scores of wDoc, wEmo, wAch, and wCrea. Likewise, by adding scores of wRecog, wAff, and wPunish, composite scores of extrinsic writing motivation were calculated. Finally, composite scores were correlated with examination marks of Bengali (first language), English (second language) and total marks. Table 3 shows that both intrinsic and extrinsic

Table 3. Correlation matrix of writing motivation and examination marks $(n=200)$

\begin{tabular}{l|l|l|l|l|l|l}
\hline Variables & 1 & 2 & 3 & 4 & 5 & 6 \\
\hline 1.Extrinsic & 1.00 & & & & & \\
\hline 2.Intrinsic & -1.00 & 1.00 & & & & \\
\hline 3.Bengali & $-0.31^{* *}$ & $0.31^{* *}$ & 1.00 & & & \\
\hline 4.English & $0.16^{*}$ & $-0.16^{*}$ & $0.22^{* *}$ & 1.00 & & \\
\hline 5.Arithmetic & $-0.24^{* *}$ & 0.24 & $0.79^{* *}$ & $0.28^{* *}$ & 1.00 & \\
\hline 6. Total & $-0.19^{* *}$ & $0.19^{* *}$ & $0.37^{* *}$ & $-0.45^{* *}$ & $0.36^{* *}$ & 1.00 \\
\hline
\end{tabular}

International Journal of Psychological Research 
writing motivation are negatively correlated with each other. This supports the basic assumption that the students concerned with intrinsic writing motivation do not want to write for extrinsic motivating factors and vice versa. Extrinsic motivation inhibits high marks in examination. Possibly due to this reason, extrinsic writing motivation was negatively correlated with examination marks in different subjects. This negative correlation suggests discriminative validity of the questionnaire. On the other hand, intrinsic writing motivation is positively correlated with examination marks suggesting high convergent validity.

Results can be understood through task components theory of Eccles et al. Eccles and her colleagues (1983) defined different components of task values, including interest value (defined as how much the individual likes the activity), attainment value (defined as importance of the activity), and utility value (the usefulnes s of an activity). Significant correlation of intrinsic motivation and academic achievement suggests that students find high task values in learning first language and mathematics. Finding high task values, they possibly feel flow experience (Csikszentmihalyi,1978), losing track of time and self-awareness when becoming completely involved in an activity such as writing a book resulting high score in the examinations of first language and arithmetic.

\section{General Discussion}

The research has examined both conceptual and measurement issues arising from the development of construct of writing motivation. The findings suggest that writing motivation has two broad latent traits as intrinsic (writing for own sake) and extrinsic (writing to satisfy others) writing motivation. Intrinsic writing motivation is positively correlated with school examination performance and extrinsic is negatively related. Furthermore both are inversely correlated with each other suggesting both convergent and discriminating validity.

Second, study highlights correspondence analys is in extracting latent structure of variables like principal component analysis. CA also provides the information that maximum variances of writing motivation was explained by two axis of correspondence map. Relation between correspondence analysis and hierarchical cluster analys is is noted.

Third, pattern of relation of two latent constructs with academic performance gives insight as how to teach students for development of intrinsic writing motivation. Results show that student performs better in the examination when he is intrinsically motivated to read.

\section{REFERENCES}

Andrews,D.F. (1978). Exploratory data analysis. In W.H. Kruskal, W.H. and J.M. Tanur. (Eds.). International Encyclopedia of Statistics.

Campell, D. T., \& Fiske, D. W. (1959). Convergent and discriminant validation by the multitraitmultimethod matrix. Psychological Bulletin, 56, 81-105.

Csikszentmihalyi, M. (1978). Intrinsic rewards and emergent motivation. In M.Lepper \& D. Green (Eds.) The hidden costs of reward: New perspectives on the psychology of motivation. (pp.205-216).Hillsdale, NJ:Erlbaum.

Dutta Roy,D. (2003). Development Of The Questionnaire For Assessment Of Writing And Writing Motivation Of Boys And Girls Of Grades III And IV. Project report submitted to the Indian Statistical Institute, Kolkata.

Greenacre, M. and Blasius, Jong (1994). Correspondence analysis in the social sciences:Recent developments and applications. New York.: Academic press.

Judd,C.M. (1981). Estimating the effect of social interventions. Cambridge: Cambridge Press.

Stanovich,K.E. \& Cunningham, A.E. (1992). Studying the consequences of literacy within a literature society: The cognitive correlates of print exposure. Memory and cognition, 20,51-68.

Dutta Roy. D. (2004). Teaching models of writing motivation. In Panch Ramalingam, (Ed.). Psychological approaches to teacher education. Chennai: Inland Books. 